Article

\title{
Tackling the Downcycling Issue-A Revised Approach to Value-Corrected Substitution in Life Cycle Assessment of Aluminum (VCS 2.0)
}

\section{Christoph Koffler ${ }^{1, *}$ and Julia Florin ${ }^{2}$}

1 PE International, Inc., 344 Boylston St, Boston, MA 02116, USA

2 PE International AG, Hauptstraße 111-113, Leinfelden-Echterdingen 70711, Germany; E-Mail: j.florin@pe-international.com

* Author to whom correspondence should be addressed; E-Mail: c.koffler@pe-international.com; Tel.: +1-617-247-4477 (ext. 101); Fax: +1-617-236-2033.

Received: 24 June 2013, in revised form: 12 September 2013 / Accepted: 4 October 2013 / Published: 25 October 2013

\begin{abstract}
For some metals, downcycling appears when scrap is polluted with undesirable elements or mixed with lower quality scrap grades in a way that the material displays a change in inherent properties when recycled. The article recommends the use of different scrap class prices instead of a solitary secondary alloy price to represent the level of downcycling inflicted on aluminum over a product's life cycle. The price ratio between scrap price and primary aluminum price is shown to be stable across all available scrap classes for the years 2007-2010. While the revised approach to value-corrected substitution (VCS) puts a stronger emphasis on the creation of high-quality scrap by penalizing its pollution more than the original version, its key limitation is the correct identification of the appropriate point of substitution along the scrap value chain. If relevant sorting or pre-treatment steps are omitted, the substitution factor would be overcorrected, which is why it is crucial to establish the scrap value right before the scrap is either mixed with scraps from other product systems or right before it enters the remelting step.
\end{abstract}

Keywords: End-of-Life; allocation; life cycle inventory (LCI); material selection; design for environment (DfE); environmental decision making 


\section{Introduction}

The discussion of recycling in attributional Life Cycle Assessment (LCA) - and of metal recycling in particular - has been mostly around two approaches: the "avoided burden" approach, also called "End-of-Life (EoL) recyling", and the "recycled content" approach, also called "cut-off method" [1-9]. Both approaches represent variants of an "EoL allocation", where the burden of primary material production is distributed between the first and the subsequent life cycle [10]. The avoided burden approach includes the full burden of EoL recycling (i.e., collecting, sorting, remelting and casting) in the first life cycle and then allocates as much of the primary material burden to the subsequent life cycle as secondary material can be recovered. The recycled content approach, on the other hand, draws the system boundary at the point of scrap generation and allocates all burden of primary material production to the first life cycle [1].

In 2007, seventeen major metal associations officially endorsed the avoided burden approach as recommended practice for metal recycling in LCA [11]. Yet, this endorsement did not directly address the problem of "downcycling", which can be frequently observed in open-loop recycling systems, "where the material is recycled into other product systems and the material undergoes a change to its inherent properties" [10].

Downcycling appears when scrap is either polluted with undesirable elements or mixed with lower quality scrap grades in a way that the secondary material displays a change in inherent properties, such as reduced mechanical performance. A common example is the open-loop recycling of mixed, post-consumer aluminum scraps to secondary cast alloys without any significant dilution with primary material. The resulting secondary alloy could not substitute primary cast alloys in any application due to its inherent impurities (e.g., Fe, Zn, Cr) and less tight chemistry limits, which would ultimately lead to lower mechanical performance [12]. Automotive engine blocks are a common example of such bottom reservoirs for low quality alloys [13].

In such cases, crediting $100 \%$ of the burden of primary aluminum as the "avoided burden" does not seem appropriate as the secondary material is not capable of substituting its primary counterpart in all those applications that exhibit low tolerances towards these impurities such as load-carrying automotive parts in the chassis or body [14]. In addition, giving the full credit regardless of this quality loss indirectly advocates the creation of low-quality scraps, which over time degrades the global aluminum material pool and increases the overall effort to maintain the standard quality of aluminum products [15]. Value-Corrected Substitution (VCS) has been identified as one feasible way to account for quality losses over a product's life cycle.

The aim of this paper is to revise the existing VCS methodology in order to eliminate its remaining shortcomings. To achieve this goal, Section 2 critically evaluates the current approach and summarizes the basic approach as well as its advantages and shortcomings. Section 3 then continues by proposing a method revision that is essentially based on a different system boundary and the use of scrap prices instead of a solitary secondary material price to address downcycling. Section 4 then shows the results of a statistical price data analysis and discusses the remaining particularities and limitations of the revised approach before Section 5 gives a brief summary. 


\section{Critical Evaluation of the Current Approach to Value-Corrected Substitution}

The original Value-Corrected Substitution (VCS) methodology has been discussed in various publications [16-18]. In 2002, the Swiss EMPA published a research report which gives the most complete and in-depth description of the method [19]. The European Aluminium Association (EAA) today allows the use of Value-Corrected Substitution if "the inherent properties are changed" and if "the market value analysis shows a difference between the market value of the primary material and the market value of the corresponding recycled material obtained at the End-of-Life" [20]. It has further been referenced in various publications [21-23].

According to the original approach, substitution is only partial if the inherent material properties are changed over a product's life cycle in the sense of "downcycling". The environmental interventions (i.e., the life cycle inventory) of the substituted product system are then multiplied by a correction factor $\beta$ that reflects the value of the secondary output material in relation to the value of the primary input material. The same logic is applied to any secondary inputs to the primary production process using a correction factor $\alpha$ (Equations (1-3)).

$$
\begin{gathered}
\mathrm{E}_{\mathrm{pp}}\left(\mathrm{P}_{\mathrm{n}}\right)=\alpha \times \mathrm{E}_{\mathrm{pp}}-\beta \times \mathrm{E}_{\mathrm{pp}}=(\alpha-\beta) \times \mathrm{E}_{\mathrm{pp}} \\
\alpha=\left(\mathrm{p}_{\mathrm{IM}} / \mathrm{p}_{\mathrm{PM}}\right) \\
\beta=\left(\mathrm{p}_{\mathrm{OM}} / \mathrm{p}_{\mathrm{PM}}\right)
\end{gathered}
$$

with

$\mathrm{E}_{\mathrm{pp}}$ : environmental interventions related to primary production

$\mathrm{P}_{\mathrm{n}}$ : $\quad$ product $\mathrm{n}$

$\alpha$ : $\quad$ price ratio of input material into primary production to output material

$\beta$ : $\quad$ price ratio of secondary output material to primary output material

$\mathrm{p}_{\mathrm{IM}}$ : $\quad$ price of input material

p PM: $_{\text {p }} \quad$ price of primary material

p

The difference $(\alpha-\beta)$ hence expresses the degree of downcycling. Since $\alpha=1$ for products made from $100 \%$ primary aluminum, formula (1) can be reduced to:

$$
\mathrm{E}_{\mathrm{pp}}\left(\mathrm{P}_{\mathrm{n}}\right)=(1-\beta) \times \mathrm{E}_{\mathrm{pp}}
$$

The correction factor $\beta$ is established by dividing the London Metal Exchange (LME) quotation for secondary Al alloys ( $\mathrm{p}_{\mathrm{OM}}$ ) by the LME price for primary A199.7 ( $\left.\mathrm{p}_{\mathrm{PM}}\right)$, resulting in a correction factor of $\beta=0.9$, which is shown to be robust towards market fluctuations over time. The subsequent application to a case study of two different $\mathrm{Al}$ window frames ( $\mathrm{Al}$ and $\mathrm{Al}(\mathrm{Zn})$ ) is then performed by matching the alloy composition of the product scrap (incl. steel, brass, and ( $\mathrm{Zn}$ )Al components) to the alloy compositions of the LME grades. Based on "similarity", the choice is then made between a value-corrected substitution $(\beta=0.9)$ and a full substitution $(\beta=1)$.

The described procedure displays some notable benefits which shall be summarized shortly:

- It emphasizes re-collection and re-processing.

- It supports decisions towards closing material cycles that preserve high material quality. 
- It incentivizes applications that allow an efficient and value-preserving recycling.

- The two LME quotes are readily available, their ratio's stability over time has been demonstrated, and they are easy-to-use for practitioners.

But there are also some shortcomings which need to be taken into account:

- In practice, the scrap composition does not necessarily correspond to the composition of the product under study. While scrap and product composition may have been identical in the original case study of window frames [19], the described approach is not applicable to products or components which are part of and/or recycled in conjunction with other products or components of a different and unknown composition, e.g., home appliances, consumer electronics, End-of-Life vehicles, etc., which may lead to the pollution of the aluminum fraction with undesirable elements and cause a change in the inherent properties of the material.

- The LME Al alloy quotation only represents a limited array of secondary alloys, which are very similar in composition (A1-Si-Cu according to DIN 1725-5:1986 GBD-A1Si9Cu3, AA A380.1, ASTM B179, JIS H2118-1976 D12S). These "workhorse alloys" do not necessarily represent the actual quality loss in any given situation, i.e., the product-specific pollution with undesirable elements. This rather rough and hypothetical "one-price-fits-all" approach, which addresses downcycling as a digital yes-or-no-decision, therefore lacks the granularity to account for different levels of downcycling as they may occur in practice.

- As shown in Figure 1, the two processes of primary alloy production from unalloyed aluminum and secondary alloy production from Al scraps are directly comparable in terms of their function, i.e., they both produce a technical $\mathrm{Al}$ alloy from aluminum-rich raw materials. It then seems questionable to compare the price of the primary raw material input (unalloyed A199.7) to the price of the secondary material output (technical Al alloy) if the goal is to compare market values at the point of substitution.

- Also shown in Figure 1, the value (and burden) added to the product scrap by mixing it with other scraps, primary $\mathrm{Al}$ or other alloying elements in the recycling process then needs to be accounted for specifically for the product scrap under study. Since most practitioners will use the readily available inventory data published by industry to model the recycling, this introduces a bias to the calculation of the product-specific degree of downcycling as these represent industry-average, but not product-specific additions of primary aluminum, other product scraps, and/or alloying elements.

In summary, it can be said that the Value-Corrected Substitution approach in use today focuses on product composition instead of the actual scrap flow composition, that it lacks the ability to distinguish different levels of downcycling due to the use of a solitary secondary alloy price, that the chosen prices do not properly reflect the point of substitution, and that it disregards the scrap-specific addition of recycling inputs which may occur in order to create marketable secondary alloys from the product scrap under study. It is therefore worthwhile to investigate whether the method can be revised to avoid these shortcomings in future LCA studies. 
Figure 1. System boundary in the original value-corrected substitution (VCS) method.

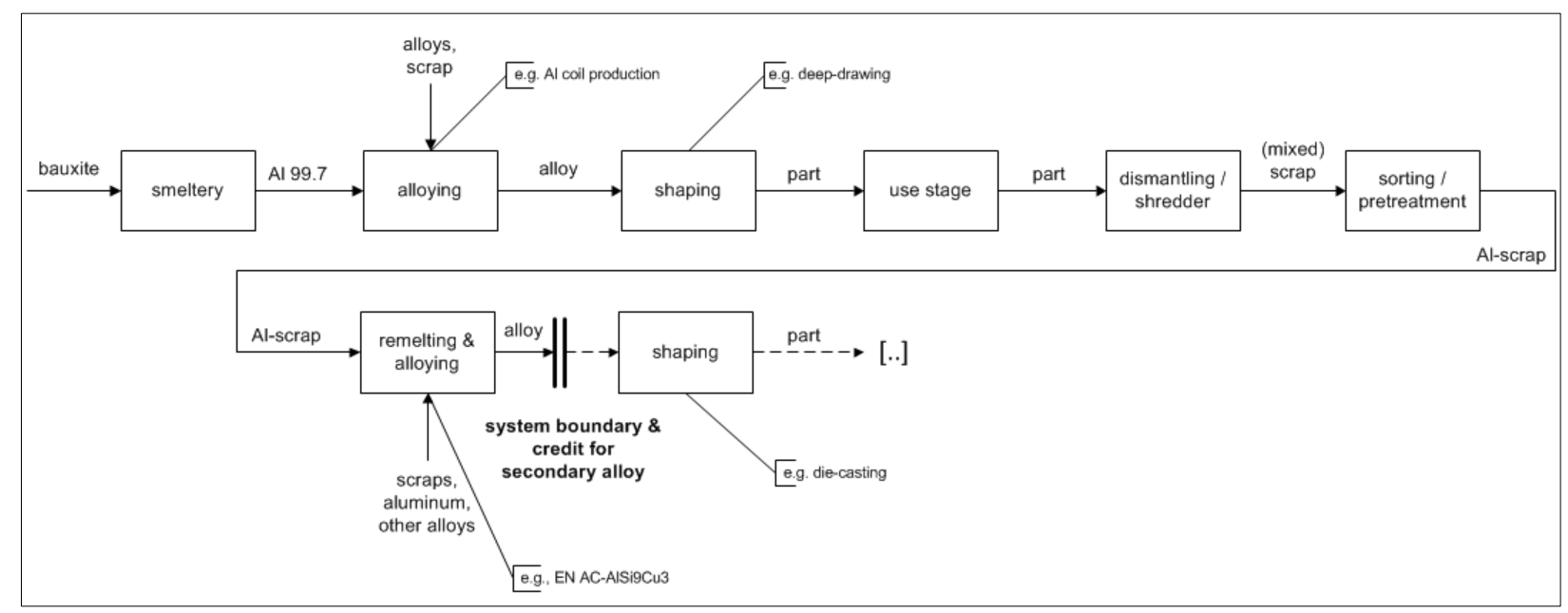

\section{Method Revision}

\subsection{Redefining the Point of Substitution}

According to the original VCS method, one of the key prerequisites for the application of Value-Corrected Substitution is that the price ratio of primary material and further material grades must be determinable for similar (re-)processing stages. As argued in the previous section and indicated by the gray rectangle in Figure 2, the recycling process of re-melting and alloying closely corresponds to the production of primary alloys. In both processes, an aluminum-rich raw material input is supplemented by additional alloy input(s) to create a material output of a desired specification. Note that the LME primary aluminum price and available inventory datasets represent A199.7, which is rarely found in technical applications without further alloying.

Following the original VCS method, one would use the price of the secondary material output (technical Al alloy) as the indicator to quantify the quality loss inflicted upon the primary raw material input (unalloyed A199.7) which can be causally assigned to the product under study. To properly reflect the point of substitution, it seems much more reasonable to either compare the prices of the two inputs into alloy making (i.e., the price of unalloyed A199.7 to the price of the product-specific scrap flow under study), or the prices of the two outputs from alloy making (i.e., the price of the primary technical Al alloy to the price of the secondary technical Al alloy).

Note that ISO 14044, Section 4.3.4.3.4 is not entirely clear on this issue as it gives both the market value of the scrap material as well as that of the recycled material in relation to market value of the primary material as an example for an economic allocation [10]. This language actually covers all three variants (input-input, output-output, input-output comparison) depending on whether one's interpretation of the term "primary material" includes or excludes an intermediate material such as A199.7.

To avoid the bias introduced by any additional alloying or scrap mixing before or during remelting, which is not properly captured by industry-average inventories on scrap remelting, it appears best to assess the quality loss over the product's life cycle by comparing the market values of the two input materials into alloy making, i.e., those of primary aluminum A199.7 and aluminum product scrap. 
Note that ISO 14044, Section 4.3.4.3.4 explicitly allows the use of the market value of scrap materials whenever physical properties are not possible or appropriate [10].

The above requires an adjustment of the system boundary: the remelting and alloying process is not considered part of the product system under study anymore, but rather considered to be the manufacturing process of the secondary material's subsequent life cycle (Figure 2). The remaining scrap flow is then credited using a value-correction factor $\gamma$ that is based on its market price:

$$
\gamma_{\mathrm{i}}=\mathrm{p}_{\mathrm{i}} / \mathrm{p}_{\mathrm{PM}}
$$

with

$\mathrm{p}_{\mathrm{i}}: \quad$ price of scrap class $\mathrm{i}$

p $\quad$ price of primary material

Figure 2. System boundary adjustment in the revised VCS method.

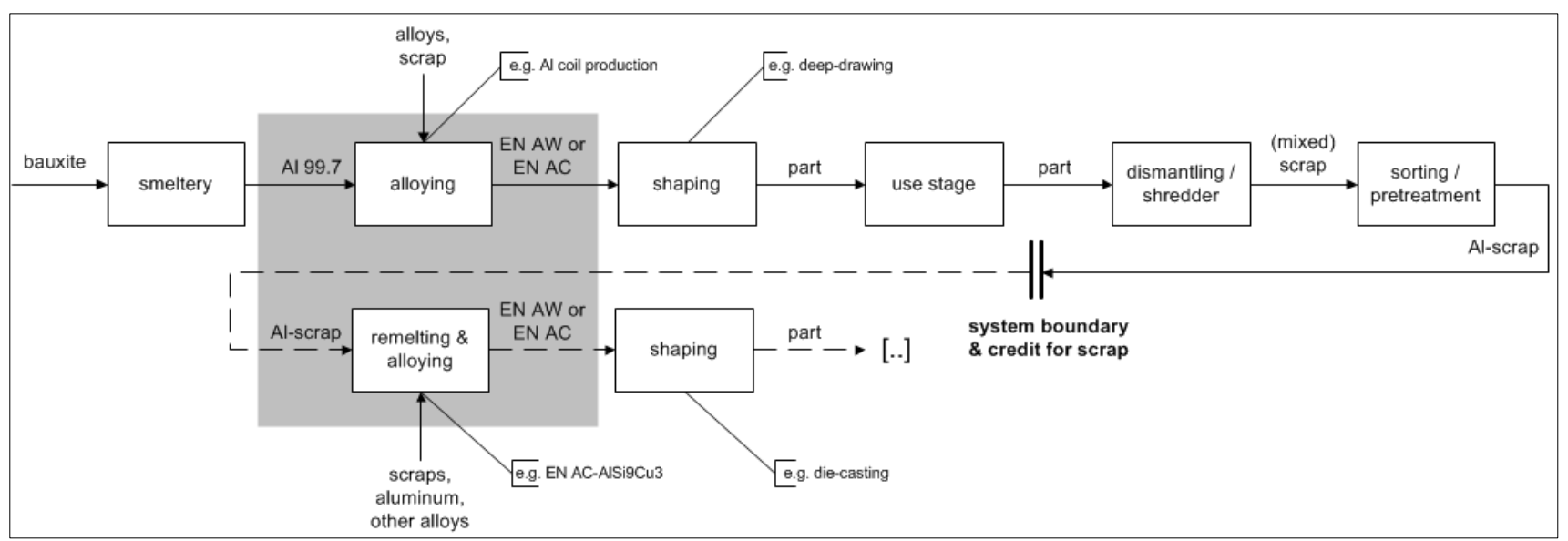

By using the scrap value instead of the secondary material value, the actual, product-specific scrap quality is accounted for. Note that the scrap price directly accounts for the subsequent effort to turn the scrap back into a marketable alloy, i.e., "clean" scraps that can be directly remelted without any addition of primary materials or other scraps would have a much higher value than heavily polluted ones that require mixing with higher quality scraps and/or dilution with primary aluminum. As a result, the bias introduced to the assessment of the product-specific degree of downcycling by the industry-average addition of any primary aluminum and/or other alloys or scraps before or during remelting can be avoided. At the same time, the methodology does not depend on a single price point for secondary Al alloy as available from LME anymore, and is therefore opened up to account for various degrees of downcycling as they appear in practice.

Nevertheless, Formula 5 is not yet complete. There are some scrap classes that only need to contain relatively low percentages of aluminum alloys, which in turn reduces their market value (in this paper, the term "aluminum alloy" refers to all traded forms of aluminum from ingot to semi-finished goods made from aluminum alloys, and is not to be confused with the pure Al content reported in elementary analyses). For all cases where the aluminum alloy content of the product under study significantly exceeds the required minimum alloy content of the scrap class that it is traded in, its value would actually be "over-corrected". In order to align the aluminum alloy contents of the product scrap under study with the respective scrap class for such cases, the value correction factor $\gamma_{i}$ would need to be 
supplemented by an "alloy content correction factor" $\mathrm{c}_{\mathrm{p}, \mathrm{i}}$, which adjusts the aluminum alloy content of the scrap class to that of the product under study (Equation (6)). That way, a higher-than-necessary (or lower-than-necessary) contribution of aluminum alloy to the traded scrap class by the product under study can be properly accounted for.

$$
\gamma_{p, i}^{*}=\gamma_{i} \times c_{p, i}=\gamma_{i} \times a_{p} / a_{\min , i}
$$

with:

$\gamma_{\mathrm{p}, \mathrm{i}}^{*}:$ content-corrected value correction factor of product $\mathrm{p}$ in scrap class $\mathrm{i}$

$\gamma_{\mathrm{i}} \quad \quad \quad$ value correction factor from Equation (5)

$c_{p, i}: \quad$ alloy content correction factor of product $p$ in scrap class $i$

$a_{p}$ : $\quad$ alloy content of product $p$ as it enters scrap class $i$

$\mathrm{a}_{\text {min,i }}$ : $\quad$ minimum permitted alloy content of scrap class $i$

Note that the content-correction constitutes a what-if scenario at this point. In practice, it is reasonable to assume that product scraps will be traded in a scrap class that corresponds either to their specific product category or to their material contents, or that they will undergo separation steps until such waste fractions are created. It is only in those cases where this is not the case, that a content correction would become necessary.

\subsection{Price Data Analysis}

Another key prerequisite for the application of Value-Corrected Substitution is that the price ratio of primary material and further material grades must be stable over time in a developed market. Availability of scrap prices has been limited in the past, but due to increasingly global and competitive scrap metal markets and advances in online trading systems, it has improved significantly over the last couple of years. ScrapIndex.com, for example, is a business-to-business web platform which tracks the prices of a multitude of different scrap classes based on actual transactions between scrap sellers and scrap buyers. For the US market, it distinguishes over 25 scrap classes for aluminum alone which generally follow the Institute of Scrap Recycling Industries (ISRI) classifications [24].

In order to assess the stability of the price ratios for use in Value-Corrected Substitution, the available historical US scrap price data (based on gross scrap masses) was procured in 2011 for the years 2007 to 2010 (no data was available for prior years), and analyzed together with the corresponding LME data on primary aluminum (cash buyer monthly averages). In addition, price data for the scrap class Automotive Aluminum Fragments was purchased for the time period of August 2010 to September 2011 and analyzed together with the corresponding LME data as no prior data was available for this more recently added scrap class.

ScrapIndex.com further distinguishes between prices for truck load (TL) and less-than-truck-load (LTL) quantities. Since truck load prices are the higher ones and therefore closer to the "true" material value, they were chosen to eliminate the bias of the delivery quantity from the analysis. 


\section{Results and Discussion}

\subsection{Price Data Analysis Results}

Figure 3 shows the results regarding the average price ratio per scrap class, the corresponding standard deviation, and the coefficient of correlation.

Figure 3. Results of aluminum price analysis for US scrap prices 2007-2010.

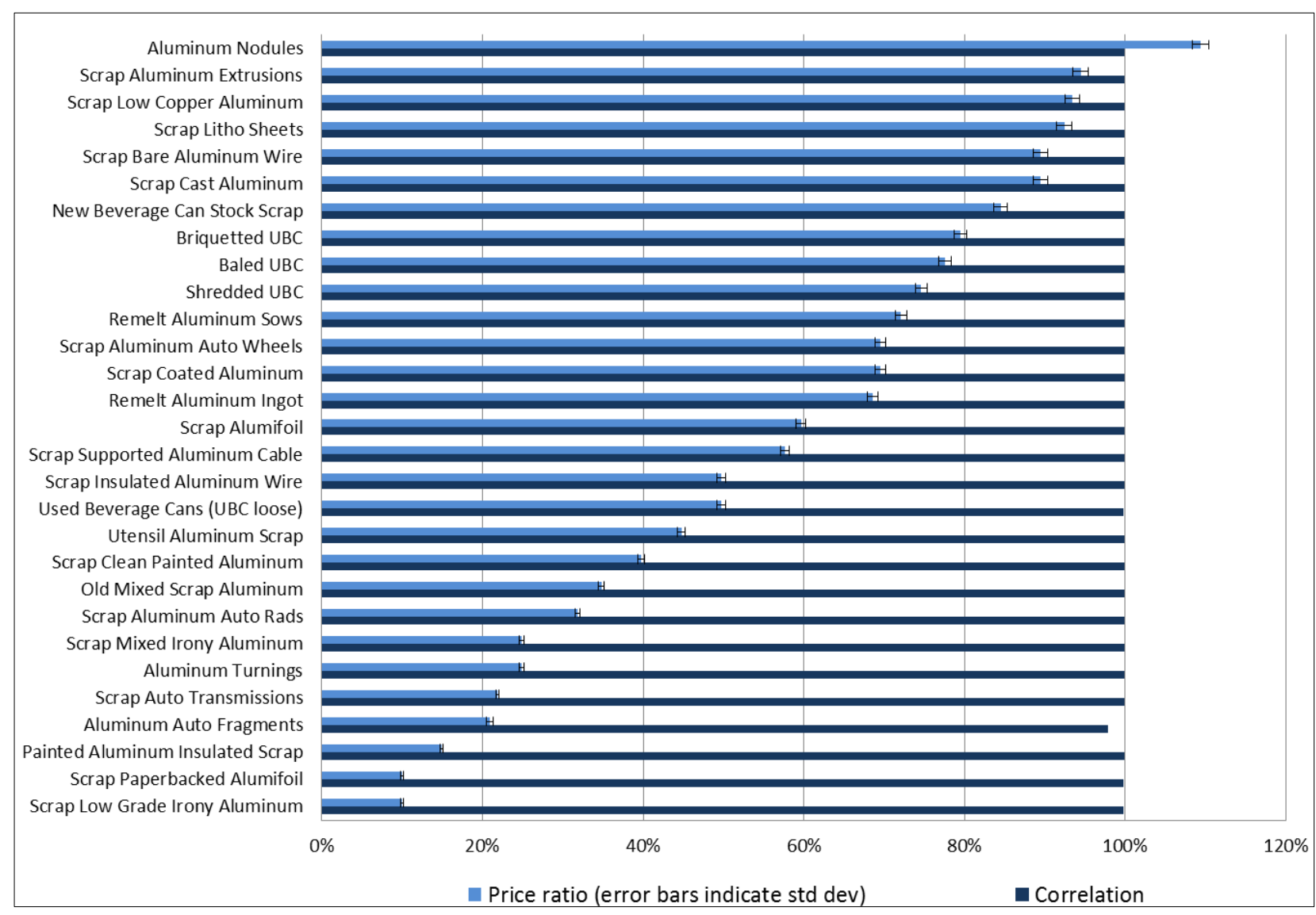

Table 1 shows that the scrap prices display a very strong correlation with the primary LME price. The lowest correlation $\rho_{\mathrm{i}}$ to be found is $97.9 \%$ (Aluminum Auto Fragments), and the highest 99.91\% (Aluminum Nodules, Utensil Aluminum Scrap, Old Mixed Scrap Aluminum, and Scrap Auto Transmissions). In fact, all scrap classes except Aluminum Auto Fragments show a correlation greater $99 \%$ as this value represents an outlier due to the limited availability of data (14 instead of 48 data points). The minimum correlation across 48 months for all other scrap classes is $99.75 \%$. The average price ratio (i.e., the proposed correction factor $\gamma_{\mathrm{i}}$ ) varies between 10\% (Scrap Low Grad Irony Aluminum and Scrap Paperbacked Aluminum Foil) and 109\% (Aluminum Nodules) with very low standard deviations between $0.2 \%$ and $1.1 \%$. 
Table 1. Correlation factor $\rho$, value correction factor $\gamma$, minimum permissible alloy content $\mathrm{a}_{\min }$, maximum content correction factor $\mathrm{c}_{\max }$ and maximum content-corrected value correction factor $\gamma^{*}$ max per scrap class i.

\begin{tabular}{lccccc}
\hline \multicolumn{1}{c}{ Scrap class i } & $\boldsymbol{\rho}_{\mathbf{i}}$ & $\boldsymbol{\gamma}_{\mathbf{i}}$ & $\mathbf{a}_{\text {min,i }}$ & $\mathbf{c}_{\mathbf{m a x}, \mathbf{i}}$ & $\gamma^{*}$ max,i \\
\hline Scrap Low Grade Irony Aluminum & $99.75 \%$ & $10 \%( \pm 0.2 \%)$ & $50 \%$ & 2.0 & $20 \%$ \\
Scrap Paperbacked Aluminum Foil & $99.75 \%$ & $10 \%( \pm 0.2 \%)$ & $\mathrm{n} / \mathrm{a}$ & $\mathrm{n} / \mathrm{a}$ & $\mathrm{n} / \mathrm{a}$ \\
Painted Aluminum Insulated Scrap & $99.87 \%$ & $15 \%( \pm 0.2 \%)$ & $\mathrm{n} / \mathrm{a}$ & $\mathrm{n} / \mathrm{a}$ & $\mathrm{n} / \mathrm{a}$ \\
Aluminum Auto Fragments & $97.86 \%$ & $21 \%( \pm 0.5 \%)$ & $50 \%$ & 2.0 & $42 \%$ \\
Scrap Auto Transmissions & $99.91 \%$ & $22 \%( \pm 0.2 \%)$ & $\mathrm{n} / \mathrm{a}$ & $\mathrm{n} / \mathrm{a}$ & $\mathrm{n} / \mathrm{a}$ \\
Aluminum Turnings & $99.87 \%$ & $25 \%( \pm 0.3 \%)$ & $90 \%$ & 1.1 & $28 \%$ \\
Scrap Mixed Irony Aluminum & $99.87 \%$ & $25 \%( \pm 0.3 \%)$ & $70 \%$ & 1.4 & $35 \%$ \\
Scrap Aluminum Auto Rads & $99.90 \%$ & $32 \%( \pm 0.3 \%)$ & $\mathrm{n} / \mathrm{a}$ & $(1.0)$ & $32 \%$ \\
Old Mixed Scrap Aluminum & $99.91 \%$ & $35 \%( \pm 0.3 \%)$ & $99 \%$ & 1.0 & $35 \%$ \\
Scrap Clean Painted Aluminum & $99.90 \%$ & $40 \%( \pm 0.4 \%)$ & $\mathrm{n} / \mathrm{a}$ & $(1.0)$ & $40 \%$ \\
Utensil Aluminum Scrap & $99.91 \%$ & $45 \%( \pm 0.4 \%)$ & $99 \%$ & 1.0 & $45 \%$ \\
Used Beverage Cans (UBC loose) & $99.85 \%$ & $50 \%( \pm 0.6 \%)$ & $\mathrm{n} / \mathrm{a}$ & $(1.0)$ & $50 \%$ \\
Scrap Insulated Aluminum Wire & $99.89 \%$ & $50 \%( \pm 0.5 \%)$ & $\mathrm{n} / \mathrm{a}$ & $\mathrm{n} / \mathrm{a}$ & $\mathrm{n} / \mathrm{a}$ \\
Scrap Supported Aluminum Cable & $99.89 \%$ & $58 \%( \pm 0.6 \%)$ & $\mathrm{n} / \mathrm{a}$ & $\mathrm{n} / \mathrm{a}$ & $\mathrm{n} / \mathrm{a}$ \\
Scrap Aluminum Foil & $99.90 \%$ & $60 \%( \pm 0.6 \%)$ & $\mathrm{n} / \mathrm{a}$ & $(1.0)$ & $60 \%$ \\
Remelt Aluminum Ingot & $99.90 \%$ & $69 \%( \pm 0.7 \%)$ & $\mathrm{n} / \mathrm{a}$ & $(1.0)$ & $69 \%$ \\
Scrap Coated Aluminum & $99.90 \%$ & $70 \%( \pm 0.7 \%)$ & $\mathrm{n} / \mathrm{a}$ & $(1.0)$ & $70 \%$ \\
Scrap Aluminum Auto Wheels & $99.90 \%$ & $70 \%( \pm 0.7 \%)$ & $\mathrm{n} / \mathrm{a}$ & $(1.0)$ & $70 \%$ \\
Remelt Aluminum Sows & $99.90 \%$ & $72 \%( \pm 0.7 \%)$ & $\mathrm{n} / \mathrm{a}$ & $(1.0)$ & $72 \%$ \\
Shredded UBC & $99.90 \%$ & $75 \%( \pm 0.7 \%)$ & $\mathrm{n} / \mathrm{a}$ & $(1.0)$ & $75 \%$ \\
Baled UBC & $99.90 \%$ & $78 \%( \pm 0.8 \%)$ & $\mathrm{n} / \mathrm{a}$ & $(1.0)$ & $78 \%$ \\
Briquetted UBC & $99.90 \%$ & $80 \%( \pm 0.8 \%)$ & $\mathrm{n} / \mathrm{a}$ & $(1.0)$ & $80 \%$ \\
New Beverage Can Stock Scrap & $99.90 \%$ & $84 \%( \pm 0.8 \%)$ & $\mathrm{n} / \mathrm{a}$ & $(1.0)$ & $84 \%$ \\
Scrap Cast Aluminum & $99.90 \%$ & $89 \%( \pm 0.9 \%)$ & $98 \%$ & 1.0 & $89 \%$ \\
Scrap Bare Aluminum Wire & $99.90 \%$ & $89 \%( \pm 0.9 \%)$ & $99 \%$ & 1.0 & $89 \%$ \\
Scrap Litho Sheets & $99.89 \%$ & $92 \%( \pm 1.0 \%)$ & $\mathrm{n} / \mathrm{a}$ & $(1.0)$ & $92 \%$ \\
Scrap Low Copper Aluminum & $99.90 \%$ & $93 \%( \pm 0.9 \%)$ & $99 \%$ & 1.0 & $93 \%$ \\
Scrap Aluminum Extrusions & $99.90 \%$ & $94 \%( \pm 0.9 \%)$ & $\mathrm{n} / \mathrm{a}$ & $(1.0)$ & $94 \%$ \\
Aluminum Nodules & $99.89 \%$ & $109 \%( \pm 1.1 \%)$ & $99 \%$ & 1.0 & $109 \%$ \\
\hline & & & & &
\end{tabular}

The ascertained price ratios also demonstrate the general correlation between material quality and scrap price, which is one of the basic assumptions behind this method. Alloy content, pollution with copper or iron, and mixing of alloy groups all lower the economic value of the scrap classes. In order to produce a marketable secondary alloy, these scraps would have to be either mixed with higher quality scraps or diluted with primary aluminum. It therefore seems appropriate that lower value scraps are also awarded a lower substitution factor. Note that this does not necessarily mean that the resulting secondary material made from these scraps displays a higher degree of downcycling, but vice versa that the effort - and environmental burden - to return to the same (primary) material quality as expressed by the A1 99.7 LME quotation would be higher for the lower-value scraps.

For all cases where a content correction as outlined in Section 3.1 should become necessary, Table 1 additionally shows the minimum aluminum alloy content $a_{\min , i}$ ascertained from scrap class 
specifications (where applicable), the corresponding maximum content correction factor $\mathrm{c}_{\max , \mathrm{i}}$ (which assumes a product aluminum alloy content of 100\%), and the resulting maximum content-corrected value correction factor $\gamma_{\text {max,i }}^{*}$ according to Equation (6).

\subsection{Discussion}

\subsubsection{Remaining Data Gaps}

For some scrap classes, the specifications do not explicitly state the minimal required aluminum alloy content, but they can be regarded as "pure" aluminum alloy scraps based on the given descriptions where any non-aluminum alloy contents below a total of $2 \%$ of mass are considered negligible [24,25]. In those cases, Table 1 denotes $c_{\text {max,i }}$ as "(1.0)". Only 5 out of 29 scrap class specifications do not specify minimum aluminum alloy contents, but are likely to contain significant amounts of foreign materials: Scrap Paperbacked Aluminum Foil, Painted Aluminum Insulated Scrap, Scrap Auto Transmissions, Scrap Insulated Aluminum Wire, and Scrap Supported Aluminum Cable.

For these scrap classes, estimates for ranges of aluminum alloy content could be established on a case-specific basis in collaboration with respective industry members or from published literature. For Scrap Auto Transmissions, for example, it is known that the aluminum alloy content of disassembled auto transmissions with a cast aluminum housing is roughly between $20 \%$ and $30 \%$ depending on whether they have been drained or not [26]. Using this range, a sensitivity analysis can be carried out on the content correction factor for an aluminum transmission housing $\left(a_{p}=100 \%\right)$ in that scrap class. In general, though, one should aim to model the EoL pathway up to the point of separation of ferrous metals, plastics, oils and other foreign materials in order to avoid the uncertainty introduced by this type of estimation.

\subsubsection{Substitution Factors Greater 100\%}

Table 1 shows that the maximum possible value correction factor is $109 \%$ for the scrap class Aluminum Nodules. "Aluminum Nodules" consist of "clean aluminum wire recovered from a chopping operation and being free of iron, copper and brass wire, aluminum hair wires and free of dirt, oil and foreign materials" [25]. This corresponds to the Aluminum Association's (AA) alloy grades 1350,8030 , and 8176 . The original VCS method discussed the possibility of a correction factor greater one hundred percent for secondary alloys due to price fluctuations and markets distortions in the original method, and recommended the use of other allocation methods in this case.

For the adjusted system boundary at hand, a correction factor greater one is nevertheless reasonable since the processing into the alloys for nodule production adds additional value to the original LME raw material grade (A199.7). If this value is preserved along the life cycle and results in a high-quality (i.e., high-value) aluminum scrap, then a credit greater 100\% primary A199.7 is fully justified if (and only if) the additional burden of producing these alloys from A199.7 is likewise accounted for in the manufacturing phase to avoid creating an overall net-negative burden. 


\subsubsection{Key Limitations}

Economic allocation is often applied in lack of better allocation keys and therefore only the second-best option to solve the allocation problem in End-of-Life recycling (see ISO 14044, Section 4.3.4.3.4). Scrap prices in particular are influenced by a wide array of aspects like supply and demand, delivery form and quantity, transportation distances, moisture or lubricant content, pre-treatment and re-melting technologies, etc., which do not influence the actual material quality in terms of their "inherent properties".

Considering the logistical effort to collect the scrap, it is obvious that this will skew the scrap price with regard to the actual material quality. Small scrap quantities that are highly dispersed over a large area would drive the logistical costs of collection and delivery upwards. However, the scrap price data displayed in Figure 3 and Table 1 are averages based on real-life transactions, hence representing an average (i.e., a moderate) logistical scenario rather than an extreme one. Also, they are explicitly based on truck load quantities (as opposed to less-than-truck-load (LTL) quantities), hence already excluding the costly collection of "scattered" scraps in low quantities.

With regard to the necessary pre-treatment and remelting technologies, the different scrap classes and prices of used beverage cans (UBC) demonstrate that the system boundary needs to be set with caution. Note that while UBCs demonstrate how delivery form will affect the scrap price, in practice, they don't lend themselves to Value-Corrected Substitution as they represent a closed-loop recycling situation where a conventional avoided burden approach is sufficient. As can be seen from Table 1, the process steps of collecting, shredding, baling and briquetting used beverage cans (UBCs) each add value to the scrap without altering the material quality in a sense that would be relevant in terms of downcycling (i.e., pollution with undesirable elements, mixing of alloy groups, etc.). Any scrap treatment that represents an "upcycling" measure in terms of scrap value therefore needs to be included in the assessment. This means that the system boundary needs to be drawn right before the scrap is either mixed with scraps from other product systems or right before it enters the remelting step. This "final" scrap value then best corresponds to the product-specific scrap quality and serves as an indicator of the hypothetical effort - and environmental burden - to return the material to its original, primary quality. While inventory data for any additional treatment steps may not be readily available as some secondary smelters perform these on-site without any separate accounting of energy or material consumptions and their additional environmental burden may be neglected from a cradle-tograve perspective, the value added to the scrap by them cannot be disregarded.

For the case of the UBCs, after it would have been shredded and decoated prior to remelting [27], the scrap would once again qualify as Scrap Low Copper Aluminum with a value-correction factor of $93 \%$. So the actual material value exceeds what is captured by all four dedicated UBC scrap classes as the scrap preparation is not entirely accounted for by these values. It is important to note that a value-correction factor of $93 \%$ closely corresponds to the magnitude of the net credit across key impact categories when applying a closed-loop avoided burden approach, where the benefit of the avoided burden of $100 \%$ primary aluminum is reduced by the additional burden of aluminum scrap recycling [28]. As UBCs are a prime example of closed-loop recycling and would be modeled using a closed-loop avoided burden approach, having the two approaches come to comparable results speaks 
to the feasibility of the described approach if (and only if) the scrap value is established at the appropriate point of substitution.

The application of the proposed approach in practice is therefore limited by the knowledge of the LCA practitioner with regard to the scrap class that is the most appropriate for the product scrap under study at the point of substitution. To properly address the above limitations, the practitioner should perform the following steps when applying the methodology:

(1). Investigate whether closed-loop recycling systems exist for the product(s) under study. Like for the discussed case of used beverage cans (UBCs), these products should be modeled using a conventional avoided burden approach rather than the proposed methodology.

(2). If the product is recycled in an open-loop recycling system, ascertain the most likely scrap class(es) that the product scrap will be traded in. The corresponding descriptions from ScrapIndex.com and the Institute of Scrap Recycling Industries (ISRI) will be helpful when doing so.

(3). Investigate whether the scrap stream will undergo any additional pre-treatment steps prior to being mixed with scraps from other product systems or entering the remelting step. If any such "upcycling" takes place, establish the appropriate higher-value scrap class that best matches the resulting scrap stream.

(4). If the aluminum alloy content of the product(s) under study is significantly different from the minimum alloy content of the chosen scrap class (see Table 1), perform a "content-correction" as described in Section 3.1.

(5). Use the resulting value-correction factor(s) to substitute primary aluminum (A199.7) with the scrap quantity in question.

(6). Perform a sensitivity analysis to test the influence of varying substitution factors on the final results of your study. This should include conventional cut-off and avoided burden scenarios.

For a critically reviewed, comparative case study applying the outlined procedure to establish the effect of this choice on the overall study results, please refer to www.alcoawheels.com/LCA.

\section{Conclusions}

The ratio of LME primary Al price and Al scrap prices has been shown to be a feasible measure to assess the level of aluminum downcycling over a product's life cycle, if (and only if) the point of substitution is identified appropriately. The main advantages of the revised Value-Corrected Substitution Procedure can be summarized as follows:

a. It incentivizes the creation of high-quality scrap in a more stringent way than the original approach by significantly increasing the penalty for the pollution of the aluminum scrap stream with undesirable elements or the mixing with lower grade scraps.

b. The use of different scrap classes provides more granularity and allows for the proper appraisal of Design-for-Recycling measures, as well as of additional "upcycling" measures in the End-of-Life phase, which is the basis for more informed decisions about costs and benefits of different recycling options. 
The developed procedure displays all the benefits of the original Value-Corrected Substitution procedure in terms of appropriateness, practicability, and ISO-compliance while avoiding its main pitfalls: the "one-price-fits-all" approach, the consideration of product instead of scrap composition, the comparison of input to output material prices, and the inclusion of additional material inputs into alloy recycling which cannot be causally assigned to the product under study. It can therefore be recommended to inform decision making for all cases where downcycling of aluminum is known to be an issue.

Its key limitation remains the correct identification of the appropriate point of substitution along the scrap value chain. If relevant pre-treatment steps are omitted, the substitution factor would be overcorrected, which is why it is crucial to establish the scrap value right before the scrap is either mixed with scraps from other product systems or right before it enters the remelting step.

While aluminum has been the prime case study for the Value-Corrected Substitution procedure in the past, the general approach can in principle be applied to other materials which encounter downcycling issues provided the available price data allows for it. Typical examples for such materials are steel, which is especially sensitive to pollution with copper, and plastics that end up in mixed scrap fractions which prevent a high-quality recycling of technical polymers. Especially in comparative studies, it is essential that the same allocation procedure is applied to account for downcycling effects of either material.

In concluding, it should be noted that the presented procedure is not meant to be the only viable solution to modeling downcycling of aluminum. Instead, it provides the LCA practitioners with an additional tool in their toolbox in cases where downcycling is known to be an issue. The procedure can therefore be recommended as part of a comprehensive analysis using different EoL allocation approaches to facilitate more informed decisions.

\section{Acknowledgments}

The authors would like to thank Christian Leroy (European Aluminum Association), Kurt Buxmann (LCA consultant to the International Aluminum Association), and J. Marshall Wang (Aluminum Association) for the open discussion and critical feedback. Please note that this acknowledgement does not imply an endorsement by any of the affiliated organizations.

\section{Conflicts of Interest}

The authors declare no conflict of interest.

\section{References}

1. Frischknecht, R. LCI modelling approaches applied on recycling of materials in view of environmental sustainability, risk perception and eco-efficiency. Int. J. Life Cycle Assess. 2010, 15, 666-671.

2. Dubreuil, A.; Young, S.B.; Atherton, J.; Gloria, T.P. Metals recycling maps and allocation procedures in life cycle assessment. Int. J. Life Cycle Assess. 2010, 15, 621-634. 
3. Klöpffer, W. Allocation rule for open-loop recycling in life cycle assessment-A review. Int. J. Life Cycle Assess. 1996, 1, 27-31.

4. Ekvall, T.; Tillman, A.M. Open-loop recycling: Criteria for allocation procedures. Int. J. Life Cycle Assess. 1997, 2, 155-162.

5. Kim, S.; Hwang, T.; Lee, K.M. Allocation for cascade recycling system. Int. J. Life Cycle Assess. 1997, 2, 217-222.

6. Ekvall, T. A market-based approach to allocation at open-loop recycling. Resour. Conserv. Recycl. 2000, 29, 91-109.

7. Yamada, H.; Daigo, I.; Matsuno, Y.; Adachi, Y.; Kondo, Y. Application of markov chain model to calculate the average number of times of use of a material in society. Int. J. Life Cycle Assess. 2006, 11, 354-360.

8. Frees, N. Crediting aluminum recycling in LCA by demand or by disposal. Int. J. Life Cycle Assess. 2008, 13, 212-218.

9. Shen, L.; Worrell, E.; Patel, M.K. Open-loop recycling: A LCA case study of PET bottle-to-fibre recycling. Resour. Conserv. Recycl. 2010, 55, 34-52.

10. International Organization for Standardization (ISO). Environmental Management-Life Cycle Assessment-Requirements and Guidelines; ISO 14044: Geneva, Switzerland, 2006.

11. Atherton, J. Declaration by the metals industry on recycling principles. Int. J. Life Cycle Assess. 2007, 12, 69-70.

12. Apelian, D. Aluminum Cast Alloys: Enabling Tools for Improved Performance; North American Die Casting Association (NADCA): Wheeling, IL, USA, 2009. Available online: http://www.diecasting.org (accessed on 11 March 2013).

13. Modaresi, R.; Müller, D.B. The role of automobiles for the future of aluminium recycling. Environ. Sci. Technol. 2012, 46, 8587-8594.

14. European Aluminum Association. The Aluminum Automotive Manual, Version 2002; European Aluminum Association (EAA): Brussels, Belgium, 2002; pp. 18-19. Available online: http://www.alueurope.eu/wp-content/uploads/2012/01/AAM-Materials-1-Resources.pdf (accessed on 13 March 2013).

15. Kevorkijan, V. Advances in recycling of wrought aluminium alloys for added value maximisation. Metallurgia 2010, 16, 103-114.

16. Werner, F.; Richter, K. Economic allocation in LCA: A case study about aluminium window frames. Int. J. Life Cycle Assess. 2000, 5, 79-83.

17. Buxmann, K. Ökobilanzen über Produkte der Gebäudehülle aus Aluminium. In Contribution to the 15. Discussion Forum on Life Cycle Assessment: Zurich, Switzerland, 19 December 2001; Discussion Forum on Life Cycle Assessment: Zurich, Switzerland, 2001. Available online: http://www.lcaforum.ch/Portals/0/DF_Archive/DF15/Fensterfassaden.pdf (accessed on 11 March 2013).

18. Frischknecht, R. ISO 14041: Glashaus oder Nebel? In Contribution to the 15. Discussion Forum on Life Cycle Assessment, Zurich, Switzerland, 19 December 2001; Discussion Forum on Life Cycle Assessment: Zurich, Switzerland, 2001. Available online: http://www.lcaforum.ch/ Portals/0/DF_Archive/DF15/Frischknecht1.pdf (accessed on 11 March 2013). 
19. Werner, F. Treatment of Aluminium Recycling in LCA-Development and Evaluation of the Value-Corrected Substitution Procedure Applied to Window Frames. In Research and Work Report 115/47; Swiss Federal Laboratories for Materials Testing and Research (EMPA): Dubendorf, Switzerland, 2002.

20. European Aluminium Association (EAA). Aluminium Recycling in LCA, Version July 2007. Available online: http://www.alueurope.eu/wp-content/uploads/2011/09/Alu_recycling_LCA.pdf (accessed on 11 March 2013).

21. Classen, M. Including the Product-Specific Recyclability into the Environmental Assessment with Environmental Product Declarations (EPDs). Presented at the International Workshop on Materials Design and Systems Analysis, Karlsruhe, Germany, 16-18 May 2006. Available online: http://www.empa.ch/plugin/template/empa/*/54738/---/l=2 (accessed on 11 March 2013).

22. Kim, H.J.; McMillan, C.; Winebrake, J.J.; Keoleian, G.A.; Skerlos, S.J. Evaluating Life Cycle Cost, Emissions and Materials Use for an Aluminum Intensive Vehicle: Preliminary Analysis. In Proceedings of the NSF Engineering Research and Innovation Conference, Knoxville, TN, USA, 7-10 January 2008; The National Science Foundation: Arlington, VA, USA, 2008.

23. Detzel, A.; Mönckert, J. Environmental evaluation of aluminium cans for beverages in the German context. Int. J. Life Cycle Assess. 2009, 14, 70-79.

24. Scrap Specifications Circular 2013. Institute of Scrap Recycling Industries (ISRI): Washington DC, USA, 2012. Available online: http://www.isri.org (accessed on 11 March 2013).

25. Scrap Aluminum Prices-USA. Available online: http://www.scrapindex.com/metal/usa/ aluminum/index.html (accessed on 11 March 2013).

26. Volkswagen AG Group Research. The DSG Dual-Clutch Gearbox Environmental Commendation; Volkswagen Group: Wolfsburg, Germany, 2008.

27. Aluminum Association (AA). Life Cycle Impact Assessment of Aluminum Beverage Cans; Aluminum Association: Washington, DC, USA, 21 May 2010. Available online: http://www. container-recycling.org/assets/pdfs/aluminum/LCA-2010-AluminumAssoc.pdf (accessed on 16 June 2013).

28. European Aluminum Association (EAA). Environmental Profile Report for the European Aluminium Industry; European Aluminum Association: Brussels, Belgium, April 2008. Available online: http://www.alueurope.eu/wp-content/uploads/2011/08/EAA_Environmental_ profile_report-May081.pdf(accessed on 16 June 2013).

(C) 2013 by the authors; licensee MDPI, Basel, Switzerland. This article is an open access article distributed under the terms and conditions of the Creative Commons Attribution license (http://creativecommons.org/licenses/by/3.0/). 